\title{
A Window to the World: Americans' Exposure to Political News From Foreign Media Outlets
}

\author{
Erik Peterson and Emily Damm* \\ Texas A\&M University \\ Department of Political Science
}

September 1, 2019

\begin{abstract}
Political communication research overwhelmingly focuses on domestic media. Internet access has relaxed geographic constraints on news use to create another possibility: exposure to political coverage from foreign media outlets. We study the frequency and form of foreign media exposure in the United States using individual-level web browsing data and a content analysis of the news this sample encountered. This reveals foreign media exposure is widespread and internationally-oriented. $85 \%$ of these individuals visited a foreign source. Foreign media accounted for $7 \%$ of all news website visits. In a within-subject analysis of over three million visits to foreign and domestic websites, individuals were substantially more likely to encounter foreign affairs coverage, and less likely to reach coverage of U.S. domestic politics, when visiting foreign news sources. These findings show how new opportunities created by a changing media landscape shape public engagement with international politics.
\end{abstract}

\footnotetext{
${ }^{*}$ Corresponding author email: erik.peterson@tamu.edu. Erik Peterson is an Assistant Professor of Political Science at Texas A\&M University. Emily Damm received her M.A. in Political Science from Texas A\&M University. The authors thank Johanna Dunaway, Matt Fuhrmann and Shanto Iyengar for helpful comments and the Bill Lane Center for the American West, the Hoover Institution, and the Knight Foundation for financial support.
} 
Internet access has vastly expanded the public's degree of choice over the news they consume (Hindman 2008). This disruption has led to greater avoidance of political information in general (Prior 2007, Arceneaux and Johnson 2013), a shift away from locally-oriented news in particular (Hopkins 2018) and a resurgence in partisan selective exposure (Stroud 2011). But this focus on domestic media has failed to address new opportunities available in the Internet era. While geographic limits on access previously restricted the public to news from local media (Mutz and Martin 2001) or national sources available throughout their country (Curran et al. 2009), online news consumption has eased these constraints to create another possibility: exposure to political news from foreign media outlets.

Foreign media outlets offer a new source of information about international politics, a coverage area under-supplied by domestic media in the United States (Soroka et al. 2013, Curran et al. 2009, Dimock and Popkin 1997), potentially increasing the public's exposure to these topics. At the same time, the American public's limited interest in foreign affairs coverage (Almond 1950, Hughes 1978), particularly when actively choosing news stories (Baum 2002), may limit the impact of foreign media access on the content they encounter. As these supply-side and demand-driven explanations for Americans' limited engagement with international political news are conflated when only examining domestic media use, studying foreign media consumption offers a rare opportunity to distinguish between them.

In this note we describe the frequency and form of Americans' foreign media exposure using a novel dataset of individual-level web browsing from a 1,504 person sample paired with a crowd-sourced content analysis of the news this sample encountered. We find that $85 \%$ visited a foreign news outlet, a substantial increase from the $29 \%$ of U.S. internet users reporting such exposure in 2003 (Best et al. 2005). Foreign media websites accounted for 7\% of all news visits. In a within-subject analysis of over three million visits to news websites, individuals were substantially more likely to encounter foreign affairs coverage, and less likely to reach coverage of U.S. domestic politics, when visiting foreign media compared to their visits to domestic media. This evidence of widespread and internationally-oriented foreign 
media exposure shows how new opportunities created by a changing media landscape shape the public's engagement with international politics.

\section{Previous Research on Foreign Media Exposure}

Three research areas relate to our focus. One establishes the pre-Internet influence of domestic information sources on public opinion about international events (e.g., Baum and Potter 2015, Berinsky 2009). Studies of "indexing" find that consensus among domestic politicians limits the types of foreign policy perspectives in the news (Bennett 1990), leading media to turn to foreign politicians for dissenting views (Hayes and Guardino 2013). Others show the market-driven U.S. media system provides less opportunity to learn about foreign affairs than media elsewhere (Soroka et al. 2013, Aalberg et al. 2010) and use this to explain the American public's comparative lack of knowledge on these topics (Curran et al. 2009, Dimock and Popkin 1997)

A second line of research isolates the effects of foreign media exposure using the crossborder spillover of television and radio signals (DellaVigna et al. 2014, Crabtree et al. 2015, Peisakhin and Rozenas 2018). While confined to border regions, these studies show foreign media can affect political behavior. Relatedly, Dragojlovic (2015) uses a survey experiment to show that foreign political figures are often as persuasive as domestic voices in shaping foreign policy views (see also Hayes and Guardino 2013).

Finally, some directly measure online exposure to foreign media outlets. Roberts (2018, Ch. 5) shows this occurs even in the presence of government-imposed barriers in China (see also Huang and Yeh 2019). Best et al. (2005) use survey self-reports to assess Americans' online exposure to foreign media in 2003 and find $29 \%$ of internet users visited a foreign site. Others use behavioral measures of online news exposure, but do not isolate foreign news use (Gentzkow and Shapiro 2011, Bakshy et al. 2015, Peterson et al. 2019). 


\section{Research Questions}

An important step towards understanding the political implications of online foreign media exposure is describing how often it occurs and the ways it differs from domestic media use. We focus on two fundamental questions. First, what is the breadth and volume of Americans' foreign media exposure? Internet access has eased geographic impediments to reaching foreign sources, but competing considerations - for instance the potential unfamiliarity of these outlets - make it unclear how broad an audience reaches them.

Second, what form does foreign media use take? One possibility is that it facilitates exposure to international political news. Supply-side explanations for the American public's limited awareness of foreign affairs emphasize the lack of coverage on this topic in the U.S. media system compared to other countries (Aalberg et al. 2010, Curran et al. 2009). Beyond this, foreign media often focus on the implications of events that involve the United States for other countries $(\mathrm{Wu} 2000) \mathrm{I}^{1} \quad$ This means foreign media visits create more potential exposure to foreign affairs than visits to domestic sources, with much of this coverage still relevant to American audiences by offering an outside perspective on international events involving the United States.

Alternatively, foreign media consumption may resemble domestic media use. Demandside explanations for the American public's limited awareness of foreign affairs emphasize a disinterest in consuming news on these topics (Almond 1950, Hughes 1978). The same content preferences that impede widespread attention to foreign affairs coverage from domestic media may also shape visits to foreign media. This is particularly relevant for online news consumption, where the ability to select individual news stories may limit inadvertent exposure to foreign affairs that occurs in other mediums (e.g., television; Baum 2002).

\footnotetext{
${ }^{1}$ While previous cross-national comparisons focus on print and television media, we later use a content analysis to confirm these divides are also present in online news coverage.
} 


\section{Breadth and Volume of Foreign Media Exposure}

We examine the web browsing behavior of 1,504 survey respondents from the United States who completed one of four political attitude surveys, focused on domestic political issues (Peterson et al. 2019), between August 2016 and March 2018. Respondents were recruited from YouGov's panel using the firm's standard approach in which an initial nonrepresentative subject pool is matched to a nationally-representative target sample.

These respondents all installed a toolbar application on their primary desktop web browser. This tracked the web pages they visited while browsing the internet in the months before each survey: $\left.\right|^{2}$ We use this to measure their online exposure to foreign media outlets. As there are many websites where such exposure might occur, we count visits to 10,256 news websites based in 190 countries outside the United States. To establish a reference for the amount of traffic to these websites, we also consider visits to 4,947 U.S.-based local and national news websites. This list comes from several sources: prominent news domains from the web traffic provider Alexa Internet, websites examined in prior studies of online news consumption and news website lists from industry and other sources (see Appendix B).

Here we briefly note, and discuss further in Appendix A, several features of this unique data. First, this sample has demographics similar to other political surveys after employing weights provided by YouGov. Second, the aggregate web traffic estimates from this sample resemble those from other sources. Finally, because we observe web traffic over varying time windows for different respondents, we show our findings persist when examining individual waves of the data (see Appendix C).

\section{Findings}

Table 1 displays the top fifteen foreign media outlets, ordered by the share of the sample that visited them once or more. Despite considering thousands of sources across the globe,

${ }^{2}$ Web tracking began after the initial August 2016 survey. Respondents received incentives from YouGov for keeping the toolbar active, but could turn it off and on as they wished. 
this reveals that foreign media consumption is heavily concentrated by geography. Outlets from the United Kingdom - most prominently the Daily Mail, BBC and The Guardian represent the entire top ten. Outside of this, cbc.ca (Canada), news.com.au (Australia), rt.com (Russia) and aljazeera.com (Qatar) also receive substantial amounts of traffic. While foreign media access has broadened Americans' news diets in important ways we consider throughout the rest of the paper, this analysis establishes that foreign media exposure is still narrow in a cultural and geographic sense.

Table 1: Most Visited Foreign News Websites

\begin{tabular}{rllrr}
\hline & Domain & Location & Share Visiting & Total Pageviews \\
\hline 1 & dailymail.co.uk & United Kingdom & 0.57 & 138940 \\
2 & theguardian.com & United Kingdom & 0.52 & 43079 \\
3 & bbc.com & United Kingdom & 0.48 & 60664 \\
4 & telegraph.co.uk & United Kingdom & 0.40 & 10282 \\
5 & independent.co.uk & United Kingdom & 0.38 & 7168 \\
6 & mirror.co.uk & United Kingdom & 0.31 & 3503 \\
7 & express.co.uk & United Kingdom & 0.29 & 3154 \\
8 & thesun.co.uk & United Kingdom & 0.27 & 4467 \\
9 & economist.com & United Kingdom & 0.22 & 5670 \\
10 & ibtimes.co.uk & United Kingdom & 0.21 & 2082 \\
11 & cbc.ca & Canada & 0.20 & 3727 \\
12 & metro.co.uk & United Kingdom & 0.19 & 1131 \\
13 & news.com.au & Russia & 0.15 & 881 \\
14 & rt.com & Australia & 0.15 & 27528 \\
15 & aljazeera.com & Qatar & 0.14 & 2632 \\
\hline
\end{tabular}

Turning to individual-level foreign media exposure, we observe substantially broader exposure to foreign media sources than in earlier examinations. $85 \%$ of this sample visited a foreign source at least once. This is a notable increase from past assessments, as Best et al. (2005) find 29\% of U.S. internet users reported visiting a foreign news website in 2003. Even when excluding the Daily Mail, which is more entertainment oriented than the other top foreign outlets, $83 \%$ of the sample still encountered a foreign source (Appendix C has additional robustness checks).

It is difficult to isolate a single explanation for this difference. On one hand, our behavioral measure does not require survey respondents to recall news use. Past work may 
underestimate foreign media exposure if respondents misremember, or are unaware of, the geographic origins of sites they visit. Beyond measurement differences, we suspect the introduction of new avenues for encountering foreign media online has increased this exposure. For instance, Best et al's (2005) study predates the growth of online social networking sites. Today social media provides a common channel for foreign media exposure as $14 \%$ of foreign media pageviews originate from Facebook or Twitter $3^{3}$

Foreign media visits also constitute a meaningful portion of the public's overall online news consumption. We compare the number of visits to three source types: national media in the United States, local media in the United States and foreign media. Consistent with discussions of the nationalized nature of contemporary media use (Hopkins 2018), the public relies heavily on nationally-oriented domestic outlets, which receive $77 \%$ of news domain visits. Local news outlets receive $16 \%$ of online news visits. Finally, foreign media visits represent $7 \%$ of the public's overall news consumption. While lower than other sources, foreign media use approaches half the volume of online local media consumption. ${ }^{4}$

\section{Form of Foreign Media Exposure}

Next we compare the news people encountered as they moved between domestic and foreign media websites. Using a supervised learning approach, we classify the content of over one million unique news articles this sample visited (see Grimmer et al. 2015, Budak et al. 2016 for other examples). We first use crowd-sourcing to assess a sample of 3,000 articles. Each article received a topic label from five different coders recruited from Amazon's

\footnotetext{
${ }^{3}$ This describes the share of visits to foreign media sites that occurred immediately after an individual was on Facebook or Twitter. This is slightly higher than domestic media visits, where $11 \%$ came after social media activity.

${ }^{4}$ We observe a similar exposure distribution when weighting the results by the amount of time individuals spent on a page (See Appendix Table C3).
} 
Mechanical Turk 5 We consider three news categories. Foreign Affairs news covers political interactions involving two or more countries (e.g., a trade deal or military conflict), one of which could be the United States, or the domestic politics of a country other than the United States (e.g., the Iranian Presidential election in 2017). News about U.S. Domestic Politics covers the internal politics of the United States (e.g., the 2016 U.S. presidential election). The final category includes all other articles (e.g., various forms of entertainment coverage). Four or more of the crowd-sourced labels agreed for $87 \%$ of the articles and Krippendorf's alpha for the labels was 0.64 (see Appendix B). We assign each article a final category based on the label it received from a majority of coders.

We train classifiers to label the broader set of articles the coders did not evaluate. Among the human-labeled articles, we predict an article's category with an elastic-net regression that uses counts of the words that appear in it as features. To distinguish the three categories, we use a "one-versus-one" approach (James et al. 2013, 355). We train three separate binary classifiers, one for each pair of categories (e.g. "Foreign Affairs" versus "Other"), and assign an article's final label based on the one it received most frequently across the three classifiers. This effectively reproduces the original, crowd-sourced labels. In five-fold cross-validation the overall accuracy is 0.93 . For the foreign affairs category in particular, this classification approach has a precision of 0.88 and recall of 0.76 (See Appendix B).

\section{Findings}

After training these classifiers, we predict labels for the entire corpus. Of the 3.3 million news articles read by this sample across domestic and foreign media, $8 \%$ focused on foreign affairs, $32 \%$ on U.S. domestic politics and $60 \%$ on other topics.

The foreign affairs category contains stories about a variety of international political events. Examining the coverage placed in this category using a structural topic model (Roberts et al. 2014) reveals coverage of international events that directly involve the United

\footnotetext{
${ }^{5} 168$ workers labeled articles. They all passed a political information screener prior to participating. See Appendix D for more information.
} 
States such as foreign interference in the 2016 Presidential Election, the Trump administration's travel ban and trade between the U.S. and China. Other coverage discusses political events outside the U.S. including Brexit negotiations, North Korean missile testing in 2017 and the Syrian Civil War. This category also includes reoccurring coverage of topics such as international trade and terrorist attacks (see Appendix D).

Having categorized this news, we compare an individual's exposure to these topics during foreign and domestic media visits using the following linear probability model:

$$
\text { Coverage Type }_{i t}=\beta_{0}+\beta_{1} \text { Foreign Media Visit }_{i t}+\alpha_{i}+\alpha_{t}+\epsilon_{i t}
$$

We regress an indicator variable for the type of coverage reached during a visit (e.g., one if labeled as foreign affairs news, zero otherwise) on an indicator variable for the type of site the visit occurred on (i.e., one if foreign, zero if domestic), individual fixed effects $\left(\alpha_{i}\right)$ that account for a person's tendency to consume a particular form of news across all types of websites (e.g., someone interested in foreign affairs news from any source) and day fixed effects $\left(\alpha_{t}\right)$ that account for events that influence exposure to certain forms of news across all websites on a given day (e.g., a focus on U.S. domestic politics on election day 2016). This specification uses within-subject variation to examine whether the same people reach different forms of political content based on the type of website they visit. This ensures any differences in the content encountered on foreign and domestic news websites are not simply because these sites receive different types of visitors.

Table 2: Comparing Topics Encountered on Foreign and Domestic News Websites

\begin{tabular}{lcc}
\hline & Foreign Affairs Coverage & U.S. Domestic Political Coverage \\
\hline Foreign Website Visit & $\begin{array}{c}0.074^{*} \\
(0.015)\end{array}$ & $\begin{array}{c}-0.190^{*} \\
(0.011)\end{array}$ \\
\hline Observations & $3,386,306$ & $3,386,306$ \\
\hline Note: & \multicolumn{2}{c}{$\begin{array}{l}\mathrm{p}<0.05 \\
\text { Robust Standard Errors, Clustered by Individual } \\
\text { Models Include Person and Day Fixed Effects }\end{array}$}
\end{tabular}


The first column of Table 2 indicates that, relative to their domestic website visits, individuals were 7.4 percentage points more likely to encounter foreign affairs coverage during visits to foreign websites. As only $7 \%$ of domestic news website visits went to foreign affairs news, this represents a sizeable jump in the likelihood of encountering this coverage. The second column shows that, compared to their domestic news website visits, these individuals were 19 percentage points less likely to encounter coverage of domestic politics in the United States when visiting foreign news websites. This is a substantial decline from domestic news website consumption, where $34 \%$ of visits went to coverage of U.S. domestic politics. Even accounting for a person's tendency to consume certain types of coverage in any setting, foreign media exposure is much more internationally oriented, and much less focused on U.S. domestic politics, than when the same people visited domestic media. ${ }^{6}$

\section{Mechanism: Supply of News From Foreign and Domestic Media}

Our theoretical discussion relies on evidence that media outside the United States provide more foreign affairs coverage than domestic sources (e.g., Aalberg et al. 2010). Our findings are consistent with this claim. However, the browsing data only show the stories people visited, not the pool of stories they could have selected from these websites.

To aid the interpretation of our results, we sample 1,200 headlines that received prominent placement on the homepages of heavily-visited foreign and domestic news sources on ten randomly selected days during this time period. We classify the topics of these headlines with the same crowd-sourcing procedure used earlier.

Figure 1 shows that, compared to domestic media outlets, the online coverage available from foreign news sources is more focused on foreign affairs (33\% of stories on foreign media relative to $14 \%$ for domestic outlets), and less focused on U.S. domestic politics ( $22 \%$ of foreign media stories compared to $51 \%$ for domestic outlets) (see Appendix F for further detail). This analysis is consistent with past comparisons of domestic and foreign media in

${ }^{6}$ Appendix E shows this same pattern using different model specifications and when only comparing foreign media to domestic outlets with a high likelihood of covering foreign affairs. 
Figure 1: Website Homepage Coverage by Topic

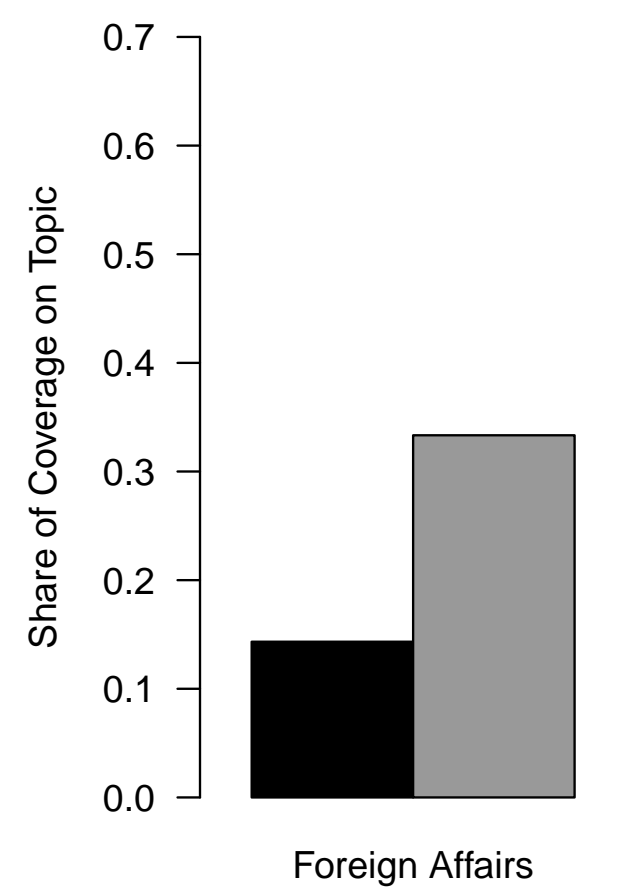

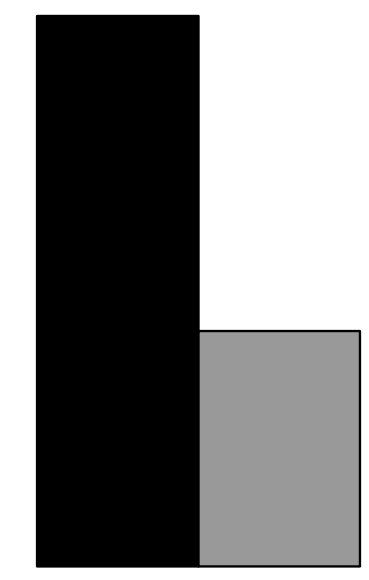

U.S. Domestic Politics
Domestic News Websites
$\square$ Foreign News Websites

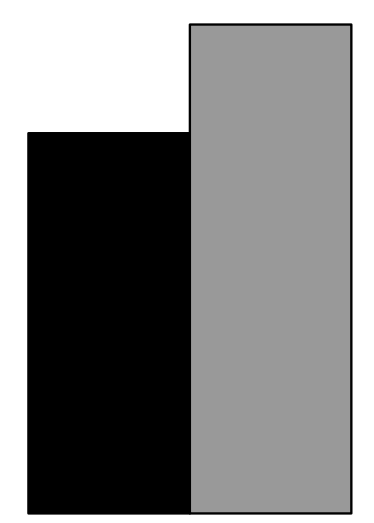

Other

print and on television. It further supports our claim that it is the distinctive supply of information available from foreign media that shapes the public's news exposure from these websites.

\section{Discussion}

Before the Internet, the public depended on domestic media. We find that online news consumption has relaxed these geographic constraints and exposure to foreign news websites is now widespread, both in absolute terms and relative to past assessments.

This study shows the benefits of contrasting foreign and domestic media consumption to address theoretical debates that are difficult to parse when only observing domestic news use. We demonstrate that when the American public leaves domestic media sources behind, they become more likely to encounter coverage of foreign affairs and less likely to reach stories about U.S. domestic politics. This is consistent with opportunity-based explanations for awareness of foreign affairs (Curran et al. 2009) and discussions of the media environment's importance in structuring political news exposure (Soroka et al. 2013). Even in an 
era of intense interest in national-level domestic politics (Hopkins 2018) and on a medium that allows individuals to choose individual stories, situational factors shape political news exposure.

These findings suggest several avenues for further inquiry. One is a focus on new questions this study raises. For example, in 2017 the U.S. Department of Justice required Russia Today, an English-language website sponsored by the Russian government and a highly visited foreign media source, to register as a foreign agent (Stubbs and Gibson 2017). This shows a need for study of particular foreign media sources, which may have consequences for opinion formation about both domestic and international events. Questions about the implications of foreign media exposure outside the United States also remain, particularly in countries where domestic media already provide substantial foreign affairs coverage (Aalberg et al. 2010) or censor content (Roberts 2018).

A second future path is revisiting models of media and foreign policy predicated on a "closed" system in which the public is restricted to domestic information sources (Rothschild and Shafranek 2017). Our evidence shows a need to test whether foreign media exposure alters previously identified patterns of opinion formation by, for instance, attenuating the influence of domestic elites and media on foreign policy opinion (e.g., Baum and Potter 2015, Berinsky 2009). While much online news consumption continues to occur on domestic sources, there may be shifts in these dynamics among those who frequently encounter foreign media sources. 


\section{References}

Aalberg, Toril, Peter van Aelst and James Curran. 2010. "Media Systems and the Political Information Environment: A Cross-National Comparison." International Journal of Press/Politics 15(3): 255-271.

Arceneaux, Kevin and Martin Johnson. 2013. Changing Minds or Changing Channels? Partisan News in an Age of Choice University of Chicago Press.

Almond, Gabriel. 1950. The American People and Foreign Policy. Harcourt.

Bakshy, Eytan, Solomon Messing and Lada Adamic. 2015. "Exposure to Ideologically Diverse News and Opinion on Facebook." Science 348(6239): 1130-1132.

Baum, Matthew A. 2002. "Sex, Lies, and War: How Soft News Brings Foreign Policy to the Inattentive Public." American Political Science Review 96(1): 91-109.

Baum, Matthew A. and Philip B.K. Potter. 2015. War and Democratic Constraint. Princeton University Press.

Bennett, W. Lance. 1990. "Toward a Theory of Press-State Relations in the United States." Journal of Communication 40(2): 102-127.

Berinsky, Adam J. 2009. In Time of War. University of Chicago Press.

Best, Samuel J., Brian Chmielewski and Brian S. Krueger. 2005. "Selective Exposure to Online Foreign News During the Conflict with Iraq." International Journal of Press/Politics 10(4): 52-70.

Budak, Ceren, Sharad Goel and Justin M. Rao. 2016. "Fair and Balanced? Quantifying Media Bias through Crowdsourced Content Analysis." Public Opinion Quarterly 80(S1): $250-271$.

Crabree, Charles, David Darmofal and Holger L. Kern. 2015. "A Spatial Analysis of the Impact of West German Television on Protest Mobilization during the East German Revolution." Journal of Peace Research 52(3): 269-284.

Curran, James, Shanto Iyengar, Anker Brink Lund and Inka Salovaara-Moring. 2009. "Media System, Public Knowledge and Democracy: A Comparative Study." European Journal 
of Communication, 24(1), 5-26.

DellaVigna, Stefano, Ruben Enikolopov, Vera Mironova, Maria Petrova and Ekaterina Zhuravskaya. 2014. "Cross-Border Media and Nationalism: Evidence from Serbian Radio in Croatia." American Economic Journal: Applied Economics 6(3): 103-132.

Dimock, Michael. and Samuel L. Popkin 1997. "Political Knowledge in Comparative Perspective." in Do the Media Govern? (Eds. Shanto Iyengar and Richard Reeves). Sage Publications. pp 217-224.

Dragojlovic, Nick. 2015. "Listening to Outsiders: The Impact of Messenger Nationality on Transnational Persuasion in the United States." International Studies Quarterly 59(1): 73-85.

Gentzkow, Matthew and Jesse M. Shapiro. 2011. "Ideological Segregation Online and Offline." Quarterly Journal of Economics 126(4): 1799-1839.

Grimmer, Justin, Sean J. Westwood and Solomon Messing. 2015. The Impression of Influence: Legislator Communication, Representation, and Democratic Accountability. Princeton University Press.

Hayes, Danny and Matt Guardino. 2013. Influence from Abroad: Foreign Voices, The Media, and US Public Opinion. Cambridge University Press.

Hindman, Matthew. 2008. The Myth of Digital Democracy. Princeton University Press.

Hopkins, Dan. 2018. The Increasingly United States. University of Chicago Press.

Huang, Haifeng and Yao-Yuan Yeh. 2019. "Information from Abroad: Foreign Media, Selective Exposure and Political Support in China." British Journal of Political Science 49(2): 611-636.

Hughes, Barry. 1978. The Domestic Content of Foreign Policy. W.H. Freeman.

James, Gareth, Daniela Witten, Trevor Hastie and Robert Tibshirani. 2013. An Introduction To Statistical Learning. Springer.

Mutz, Diana C. and Paul S. Martin. 2001. "Facilitating Communication Across Lines of Political Difference: The Role of Mass Media." American Political Science Review 95(1): 
$97-114$.

Peisakhin, Leonid and Arturas Rozenas. 2018. "Electoral Effects of Biased Media: Russian Television in Ukraine." American Journal of Political Science 62(3): 535-550.

Peterson, Erik, Sharad Goel and Shanto Iyengar. 2019. "Partisan Selective Exposure in Online News Consumption: Evidence from the 2016 Presidential Campaign." https://www.dropbox.com/s/i0w5jyo8cs765ej/partisanselectiveexposure.pdf

Prior, Markus. 2007. Post-Broadcast Democracy. Cambridge University Press.

Roberts, Margaret E. 2018. Censored. Princeton University Press.

Roberts, Margaret E., Brandom M. Stewart, Dustin Tingley, Christopher Lucas, Jetson Leder-Luis, Shana Kushner Gadarian, Bethany Albertson, and David G. Rand. 2014. "Structural Topics Models for Open-Ended Survey Responses." American Journal of Political Science 58(4): 1064-1082.

Rothschild, Jacob E. and Richard M. Shafranek. 2017. "Advances and Opportunities in the Study of Political Communication, Foreign Policy, and Public Opinion." Political Communication 34(4): 634-643.

Soroka, Stuart, Blake Andrew Toril Aalberg, Shanto Iyengar, James Curran, Sharon Coen, Kaori Hayashi, Paul Jones, Gianpetro Mazzoleni, June Woong Rhee, David Rowe and Rod Tiffen. 2013. "Auntie Knows Best? Public Broadcasters and Current Affairs Knowledge." British Journal of Political Science 43(4): 719-739.

Stroud, Natalie. 2011. Niche News: The Politics of News Choice. Oxford University Press. Stubbs, Jack and Ginger Gibson. 2017. 'Russia's RT America registers as 'foreign agent' in U.S." Reuters. November 13, 2017. https://www.reuters.com/article/us-russia-usa-media-rest russias-rt-america-registers-as-foreign-agent-in-u-s-idUSKBN1DD25B

Wu, H. Denis. 2000. "Systematic Determinants of International News Coverage: A Comparison of 38 Countries." Journal of Communication 50(2): 110-130. 


\section{Supporting Information for: "A Window to the World: Americans' Exposure to Political News From Foreign Media"}




\section{Contents}

A Appendix A: Describing Sample Composition and Web Traffic Estimates 1

A.1 Sample Composition . . . . . . . . . . . . . . . . . . . . . 1

A.2 Measuring Online Browsing Behavior . . . . . . . . . . . . . . 2

A.3 Comparing Web Traffic Estimates to Other Sources . . . . . . . . . . . . 2

\begin{tabular}{|ll}
\hline B Appendix B: Categorizing News Domains & 4
\end{tabular}

C Appendix C: Breadth and Volume of Foreign Media Exposure (Additional

$\begin{array}{ll}\text { Evidence) } & 7\end{array}$

\begin{tabular}{|ll}
\hline D Appendix D: Crowd-Sourced Article Content Labels & 9
\end{tabular}

D.1 Scraping News Content . . . . . . . . . . . . . . . . . . . . . . . . 9 9

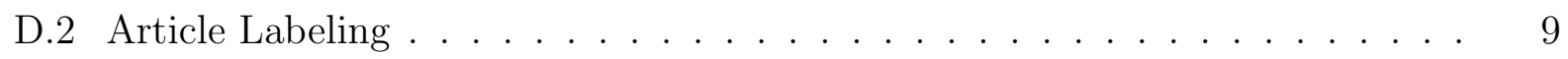

D.3 Intercoder Reliability and Agreement . . . . . . . . . . . . . . . . . 11

D.4 Supervised Learning $\ldots \ldots \ldots \ldots$

D.5 Distribution of Coverage Types $\ldots \ldots \ldots \ldots \ldots$

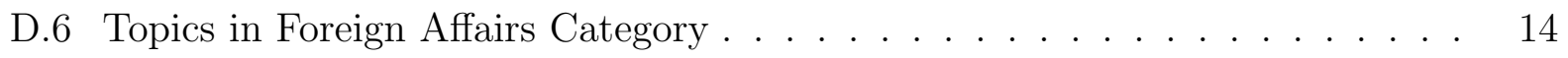

\begin{tabular}{|lll}
\hline E Appendix E: Form of Foreign Media Exposure (Additional Evidence) & 17
\end{tabular}

E.1 "Other" Coverage as an Outcome . . . . . . . . . . . . . . . . . . . 17

E.2 Bivariate Comparison $\ldots \ldots \ldots \ldots \ldots \ldots \ldots \ldots$

E.3 Using Person-Day Fixed Effects $\ldots \ldots \ldots \ldots$

E.4 Dropping Daily Mail . . . . . . . . . . . . . . . . . . . . . . . . . . . . . . 19

E.5 Comparison to Domestic Outlets with High Capacity for Foreign Affairs Coverage . . . . . . . . . . . . . . . . . . . . . 19

\begin{tabular}{|ll}
\hline F & Appendix F: Supply of News from Foreign and Domestic Media 21
\end{tabular} 


\section{A Appendix A: Describing Sample Composition and Web Traffic Estimates}

\section{A.1 Sample Composition}

Respondents for this study were recruited using YouGov's standard approach of matching an initially non-representative online sample to a nationally representative target. This has been utilized in a variety of studies of public opinion, including the Cooperative Congressional Election Study. We received weights for each survey wave to help correct for any remaining imbalances between the realized sample and the initial target sample. The table below displays the demographic composition of the unweighted, pooled sample of all respondents where we have web tracking data available across the three survey waves as well as the weighted samples from each individual survey wave. Because there was a panel structure to the survey data in which some respondents were re-interviewed in multiple surveys, the total number of unique respondents is less than the sum of respondents across the three survey waves. We also display the same information for the 2016 CCES, to provide a reference point for the survey demographics. Our sample composition is generally close to these benchmarks, although even our weighted samples contain slightly more individuals with a college or post-graduate degree and a slightly greater share of Democrats. 
Table A1: Sample Demographics

\begin{tabular}{rl|llll}
\hline Survey & $\begin{array}{l}\text { 2016 CCES } \\
\text { (Weighted) }\end{array}$ & $\begin{array}{l}\text { Pooled } \\
\text { (Unweighted) }\end{array}$ & $\begin{array}{l}\text { Wave 1 } \\
\text { (Weighted) }\end{array}$ & $\begin{array}{l}\text { Wave 2 } \\
\text { (Weighted) }\end{array}$ & $\begin{array}{l}\text { Wave 3 } \\
\text { (Weighted) }\end{array}$ \\
\hline Black & 0.12 & 0.07 & 0.12 & 0.11 & 0.11 \\
Hispanic & 0.07 & 0.05 & 0.07 & 0.08 & 0.10 \\
White & 0.73 & 0.81 & 0.75 & 0.76 & 0.74 \\
Other Race & 0.07 & 0.07 & 0.06 & 0.05 & 0.05 \\
College Plus & 0.26 & 0.41 & 0.32 & 0.33 & 0.38 \\
Female & 0.52 & 0.52 & 0.54 & 0.52 & 0.53 \\
Age & 47.1 & 53.76 & 49.41 & 50.14 & 49.73 \\
Income $(\$)$ & 64581.65 & 66190.82 & 62079.76 & 65145.46 & 65698.06 \\
Democrat & 0.46 & 0.54 & 0.53 & 0.54 & 0.50 \\
Republican & 0.36 & 0.33 & 0.34 & 0.32 & 0.35 \\
Independent & 0.18 & 0.13 & 0.13 & 0.14 & 0.15 \\
\hline Sample Size & 64600 & 1504 & 1040 & 1069 & 1080 \\
\hline
\end{tabular}

In Appendix $\mathrm{C}$ of this supplemental appendix we show our descriptive findings on the breadth and volume of foreign news exposure do not change 1) when we examine individual survey waves rather than the pooled sample or 2) when we incorporate the survey weights into our web traffic estimates.

\section{A.2 Measuring Online Browsing Behavior}

These survey respondents had all previously agreed to install an online toolbar, from Wakoopa, on their primary desktop web browser. When active, this toolbar tracked the individual urls they encountered while browsing the internet. Respondents were able to turn the toolbar on and off as they wished, but received incentives for keeping it active.

\section{A.3 Comparing Web Traffic Estimates to Other Sources}

One concern is how the results of this approach to measuring online web traffic compare with other sources. This section compares several metrics of web traffic obtained from the data source we use here, to those from Comscore, an alternative source of web traffic. We do so by comparing data from our sample in October 2016, during the initial wave of data collection, to levels of traffic in Comscore during that same time. We rely on this comparison as it is the most recent month of data for which we had access to Comscore. 
We paired aggregate traffic data from our set of Wakoopa panelists to Comscore traffic data for two sets of websites 1) the top 500 websites of any type in our dataset and 2) a set of 255 high-traffic political websites from our list. This focus on high-traffic sites is necessary because ComScore does not record traffic counts for sites that fall below a threshold for web traffic, limiting our ability to make comparisons across those lower-traffic sites. We compared web traffic patterns for three different measures including 1) the share of active panelists with at least one visit to a domain on a given day (closest to the approach used in Gentzkow and Shapiro 2011), 2) the share of all web traffic to different web domains and c) the overall volume of traffic to various web domains (i.e., the number of daily visits made to a domain by active panelists).

Table A2: Comparison to Other Web Traffic Data

\begin{tabular}{llll}
\hline & Daily Visitor Share (1 or More Visits) & Traffic Share & Visits per Panelist \\
\hline Top 50 (All Sites) & 0.82 & 0.95 & 0.95 \\
Top 500 (All Sites) & 0.82 & 0.95 & 0.95 \\
Top 50 (Political Site List) & 0.74 & 0.55 & 0.54 \\
Full Political Site List & 0.84 & 0.67 & 0.67 \\
\hline
\end{tabular}

Across these comparisons the correlation between the share of users visiting a domain at least once on a given day exceeds .8 for the entire website list and .7 when focusing just on political websites. In terms of traffic share there are stronger relationships between the two sources of data for the entire website list (above .9) than when just focusing on the political website list (above .5). 


\section{B Appendix B: Categorizing News Domains}

Our list of domestic and foreign media websites comes from several sources. We used a multi-stage process to ensure we observe news consumption from the wide array of online media outlets individuals could potentially reach.

First, we considered high-traffic news domains that appeared in Alexa Internet's (alexa.com) traffic ranking among the either top 500 global websites or country-specific lists for the United States, Canada and Mexico. Second, we added news domains from two prior academic studies of online media consumption (Bakshy et al. 2015). Third, we added local media websites in the United States using the Editor $\&$ Publisher DataBook (for daily newspapers), a wikipedia listing of local TV station websites (independently verified by one of the researchers), and lists of weekly newspaper websites in the United States from www.world-newspapers.com and www.w3newspapers.com. Fourth, we added a broader set of low-traffic news websites from outside the United States that are listed on either www.world-newspapers.com or www.w3newspapers.com. These sources provided information about media outlets in 190 countries outside the United States and include websites in english as well as other languages.

We made several edits to this combined list prior to the analysis. We remove domains with descriptions that indicate they are clearly focused on non-political topics (e.g., sports, fash-

ion and tourism websites; commercial websites like Amazon.com) and would not provide a great deal of political coverage. We also removed non-profit and government organizations that appeared on these lists, but do not operate as a media outlets.

Finally, in determining the placement of a news organization, we considered the geographic location of its headquarters. This is straightforward in nearly all cases, but does mean that subsidiary sites, for instance huffingtonpost.co.uk, are considered as US-based. A small number of online-only websites with content that focused on American politics did not pro- 
vide a specific location or contact address, these were coded as US-based.

Our final list includes 15,203 news websites based in 192 countries. 4,947 (33\% of the list) are based in the United States. 10,256 (67\% of the list) are based outside the United States. The tables below display the top traffic sites among the U.S.-based national and local news sources, ordered by the share of the sample that visited them at least once.

Table B1: Most Visited National News Websites

\begin{tabular}{rlrr}
\hline & Domain & Share Visiting & Total Pageviews \\
\hline 1 & huffingtonpost.com & 0.72 & 311716 \\
2 & cnn.com & 0.72 & 166281 \\
3 & washingtonpost.com & 0.70 & 322917 \\
4 & nytimes.com & 0.70 & 263953 \\
5 & usatoday.com & 0.68 & 40330 \\
6 & foxnews.com & 0.67 & 226312 \\
7 & Yahoo News & 0.61 & 200952 \\
8 & cbsnews.com & 0.60 & 38989 \\
9 & businessinsider.com & 0.60 & 37118 \\
10 & forbes.com & 0.57 & 32829 \\
11 & abcnews.go.com & 0.57 & 22561 \\
12 & buzzfeed.com & 0.56 & 67687 \\
13 & nbcnews.com & 0.54 & 50473 \\
14 & MSN News & 0.50 & 190281 \\
15 & npr.org & 0.50 & 37118 \\
16 & time.com & 0.49 & 15225 \\
17 & politico.com & 0.45 & 67126 \\
18 & usnews.com & 0.45 & 11197 \\
19 & thehill.com & 0.44 & 38868 \\
20 & wsj.com & 0.43 & 25828 \\
\hline
\end{tabular}


Table B2: Most Visited Local News Websites

\begin{tabular}{rlrr}
\hline & Domain & Share Visiting & Total Pageviews \\
\hline 1 & latimes.com & 0.56 & 34132 \\
2 & nypost.com & 0.53 & 19576 \\
3 & nydailynews.com & 0.46 & 28427 \\
4 & cbslocal.com & 0.44 & 21487 \\
5 & sfgate.com & 0.43 & 43133 \\
6 & chicagotribune.com & 0.42 & 14745 \\
7 & hollywoodreporter.com & 0.37 & 10724 \\
8 & chron.com & 0.33 & 17045 \\
9 & miamiherald.com & 0.32 & 5394 \\
10 & patch.com & 0.29 & 11688 \\
11 & washingtontimes.com & 0.29 & 13008 \\
12 & bostonglobe.com & 0.28 & 6274 \\
13 & observer.com & 0.23 & 2750 \\
14 & nj.com & 0.22 & 6914 \\
15 & dallasnews.com & 0.22 & 11424 \\
16 & mercurynews.com & 0.21 & 2961 \\
17 & al.com & 0.21 & 3732 \\
18 & seattletimes.com & 0.20 & 12745 \\
19 & azcentral.com & 0.20 & 4996 \\
20 & freep.com & 0.19 & 4922 \\
\hline
\end{tabular}




\section{Appendix C: Breadth and Volume of Foreign Media Exposure (Additional Evidence)}

The below table shows that estimates of the breadth of foreign media exposure, operationalized as the share of the sample that visits a foreign media source at least once, are largely stable across individual waves of the data and whether using or not using the weights provided by YouGov to correct for discrepancies between the realized sample and the initial, nationally-representative target frame.

Table C1: Share Visiting Foreign Media by Wave

\begin{tabular}{rrrr}
\hline & Wave 1 & Wave 2 & Wave 3 \\
& $($ Aug 1, 2016 - Nov 7, 2016) & (Nov 8, 2016-Sep 15, 2017) & (Sep 16, 2017 - Mar 3, 2018) \\
\hline Unweighted & 0.77 & 0.83 & 0.78 \\
Weighted & 0.72 & 0.81 & 0.79 \\
\hline
\end{tabular}

This same pattern holds when examining the volume of media exposure from different types of sources, operationalized here as the share of all pageviews to news websites that occur on given type of source (i.e., Foreign, National, or Local). Across panel waves and whether weighting the sample or not, $5-8 \%$ of news website pageviews occur on foreign media sources, although this number is slightly higher in the waves that occur after the 2016 election.

Table C2: Share of Media Website Pageviews to Source Type by Wave

\begin{tabular}{lrrr}
\hline & Wave 1 & Wave 2 & Wave 3 \\
& $($ Aug 1, 2016 - Nov 7, 2016) & (Nov 8, 2016 - Sep 15, 2017) & (Sep 16, 2017 - Mar 3, 2018) \\
\hline International (Unweighted) & 0.06 & 0.08 & 0.07 \\
International (Weighted) & 0.05 & 0.08 & 0.08 \\
\hline National (Unweighted) & 0.80 & 0.75 & 0.76 \\
National (Weighted) & 0.80 & 0.73 & 0.75 \\
\hline Local (Unweighted) & 0.15 & 0.17 & 0.17 \\
Local (Weighted) & 0.14 & 0.19 & 0.17 \\
\hline
\end{tabular}

We also consider the amount of time that respondents spend on these pages, to account for the possibility they spend different amounts of time on foreign and domestic news websites. 
Table C3: Share of News Use Weighted by Time on Page

\begin{tabular}{llr}
\hline & Source Type & Share of Time on Source Type \\
\hline 1 & International & 0.10 \\
2 & National & 0.76 \\
3 & Local & 0.15 \\
\hline
\end{tabular}

When we weight visits by the amount of time that respondents spend on a given page, foreign media sources receive an even greater amount of attention from the panel $(10 \%)$ then when we use pageviews as the unit of analysis. 


\section{Appendix D: Crowd-Sourced Article Content Labels}

\section{D.1 Scraping News Content}

After removing visits to the home page of websites, we scraped the contents of urls visited by respondents from a set of 355 high-traffic news outlets, considered in a prior study of 2016 election news consumption, as well as all the foreign media outlets visited by this sample that were not scraped in this prior analysis. Relative to the overall browsing volume results, this section mainly excludes low-traffic local news websites in the United States. This results in a slightly higher share of these scraped visits (9\%) occurring on foreign media sites relative to the previous sections.

We successfully scraped 1,173,052 articles this panel visited on these pages. Accounting for articles read by multiple individuals, these articles received 3,386,306 pageviews. This represents $82 \%$ of the article pageviews by this sample. We processed the text using gooseextractor to isolate the content of the news article from other pieces of extraneous text.

\section{D.2 Article Labeling}

We used an iterative coding scheme to develop a set of labels for respondents to apply. Our final scheme includes a list of non-political topics, so coders would not feel pressure to label articles as always containing some political information. Among political topics we had respondents label the country of origin as well as the topic, we aggregate them for our final analysis as there were very few articles that focused exclusively on the domestic politics of foreign countries and our focus on foreign affairs coverage as a broader concept includes some topics that directly involve the United States and some that do not.

Coders were recruited from Amazon's Mechanical Turk. To become eligible for the task they were required to pass a three-item political knowledge study indicating awareness of U.S. Domestic political figures, needed for the U.S. Domestic category, as well as awareness of the 
British Monarchy, needed to exclude this group from the international political categories later on. Coding of the training set proceeded in four separate batches. We placed a limit of 250 items per coder for each batch to limit the influence of any individual on the resulting labels.

The instructions outlined the political categories and offered examples of each to provide clarity on when the labels would apply.

Figure D1: Instructions

\begin{tabular}{|c|c|c|}
\hline \multicolumn{3}{|c|}{ See the Definition below for more details on each category and Examples } \\
\hline Topic & Definition & Examples \\
\hline $\begin{array}{l}\text { Domestic Political (United States } \\
\text { Only) }\end{array}$ & Politics inside the United States & $\begin{array}{l}\text { Coverage of a U.S. Election (e.g., } 2016 \text { Presidential Election). Speech } \\
\text { or actions of a political leader (e.g., U.S. President Donald Trump) }\end{array}$ \\
\hline Domestic Political (Non-US) & Politics inside a country other than the United States & $\begin{array}{l}\text { Coverage of a Non-US Country's Election Process (e.g., the German } \\
\text { Federal Election in 2017). Speech or actions of a political leader (e.g., } \\
\text { U.K. Prime Minister Theresa May) }\end{array}$ \\
\hline $\begin{array}{l}\text { International Political (United } \\
\text { States Involvement) }\end{array}$ & $\begin{array}{l}\text { Political interaction between two or more countries that involves the } \\
\text { United States. }\end{array}$ & $\begin{array}{l}\text { Trade deal involving the US. Foreign political leader visits the US. US } \\
\text { Involvement in military conflict. }\end{array}$ \\
\hline $\begin{array}{l}\text { International Political (No US } \\
\text { Involvement) }\end{array}$ & $\begin{array}{l}\text { Political interaction between two or more countries that does not } \\
\text { involve the United States. }\end{array}$ & Brexit. Chinese Government Aid to Africa. \\
\hline
\end{tabular}

In the resulting scheme we also provided a number of other categories to ensure coders did not feel pressure to select the political categories and provide examples of other types of non-political coverage that might be present. The interface used to provide these labels is displayed below. 
Figure D2: Coding Input

International News Article Categorization Instructions (Click to expand)

Title: \$\{title\}

$\$$ body\}

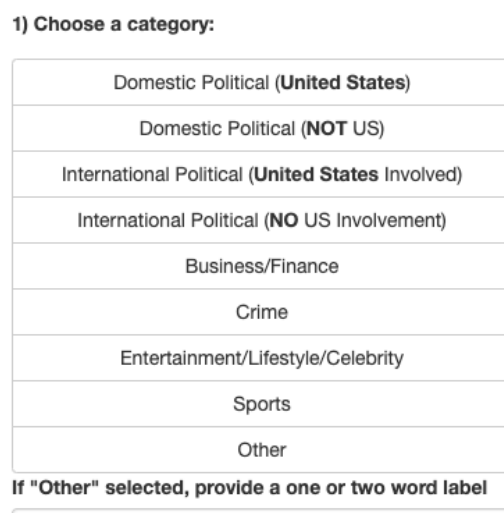

We combined these individual ratings into three broad categories. Articles labeled as "Domestic Political (NOT US)," "International Political (United States Involved)" and "International Political (NO US Involvement)" are grouped together as coverage of Foreign Affairs. "Domestic Political (United States)" are labeled as coverage of U.S. Domestic Politics. Articles labeled as "Business/Finance," "Crime," "Entertainment/Lifestyle/Celebrity," "Sports," or "Other" are grouped together in the Other coverage category.

\section{D.3 Intercoder Reliability and Agreement}

The table below displays intercoder reliability among the pooled sample of articles and individually for the foreign and domestic news sources. Overall there is a high degree of reliability to the five labels provided by the coders, although it is slightly lower for the domestic news source coding than for the foreign sources.

\begin{tabular}{rrrr}
\multicolumn{4}{c}{ Table D1: Intercoder Reliability (3 Category Scheme) } \\
\hline & Pooled & Foreign Sources & Domestic Sources \\
\hline Krippendorf's $\alpha$ & 0.64 & 0.66 & 0.53 \\
No. Articles & 3000.00 & 2000.00 & 1000.00 \\
\hline
\end{tabular}

Turning to the individual label categories, the table below shows the percent of articles on which four or five of the labels agreed about the placement of an article in one of the three categories. From this it is clear there is a similarly high agreement in the pooled sample, 
among only foreign sources or among domestic sources about whether an article should receive the "Foreign Affairs" label, an important point since much of our analysis is centered on this particular category.

Table D2: Share of Articles with Agreement among 4 or 5 Coders by Category

\begin{tabular}{rrrr}
\hline & Pooled & Foreign Sources & Domestic Sources \\
\hline U.S. Domestic Politics & 0.91 & 0.96 & 0.82 \\
Foreign Affairs & 0.92 & 0.91 & 0.94 \\
Other & 0.88 & 0.90 & 0.84 \\
\hline
\end{tabular}

The primary source of difficulty appears to be determining the "Other" and "U.S. Domestic Politics" coverage on Domestic sources, a task that may be complicated by more articles in this area with some mention of U.S. Domestic politics even as they primarily focus on other issues.

\section{D.4 Supervised Learning}

We used an elastic-net logistic regression $(\alpha=0.5)$ to predict an article's label based on a document term matrix that contains counts of the 1,000 most common words in the corpus (after stemming and removing stopwords).

We relied on a one-v-one classification approach in which we aggregate the results of three separate binary classifiers that distinguish each pair of categories. From this process there are a small number of articles (25) that comprise less than $1 \%$ of the training set and receive idiosyncratic ratings from the three classifiers (e.g., Rated as "Domestic U.S." by the Domestic-Foreign classifier, "Foreign" by the Foreign-Other classifier and "Other" by the Domestic-Other classifier), we placed these articles in the "Other" category for what follows.

We used five-fold cross-validation to select the threshold for classifying an article as "in" one of the categories for each binary classifier. These thresholds are displayed below. When focusing on this, we selected thresholds that maximize the the F1-score of the lower prevalence 
category. This balances the precision and recall of these classifiers across these less common categories. Because foreign affairs news is less prevalent in this coverage than U.S. domestic politics or other forms of news coverage, a failure to do so would result in poor accuracy and recall for this lower prevalence category.

\begin{tabular}{|c|c|}
\hline & \\
\hline 1 v. 2 & 0.32 \\
\hline 1 v. 3 & 0.33 \\
\hline 2 v. 3 & 0.32 \\
\hline
\end{tabular}

Finally, we evaluated the performance of this classifier among the set of human-labeled articles using five-fold cross-validation. This produces an overall accuracy of 0.93 in terms of recovering these labels. There is also good performance when we examine recall and precision for each of the categories, indicating the classifier's overall performance does not come at the expense of the lower prevalence foreign affairs and U.S. domestic news categories.

Table D4: Recall and Precision by Class (Five-fold CV)

\begin{tabular}{rrr}
\hline & Recall & Precision \\
\hline Foreign Affairs & 0.76 & 0.88 \\
U.S. Domestic Politics & 0.91 & 0.93 \\
Other & 0.97 & 0.93 \\
\hline
\end{tabular}

\section{D.5 Distribution of Coverage Types}

After training these classifiers on the set of human-labeled articles, we apply this approach to the entire corpus of articles. The table below considers the distribution of article topics for the entire corpus and separately for domestic and foreign media visits. 
Table D5: Article Content (Overall and by Media Type)

\begin{tabular}{rrrr}
\hline & Overall & Domestic Media & Foreign Media \\
\hline Foreign Affairs & 0.08 & 0.07 & 0.11 \\
U.S. Domestic & 0.32 & 0.34 & 0.08 \\
Other & 0.60 & 0.58 & 0.80 \\
\hline No. Articles & 3386306.00 & 3081498.00 & 304808.00 \\
\hline
\end{tabular}

\section{D.6 Topics in Foreign Affairs Category}

After using supervised learning to classify articles into the foreign affairs category, we explore the various types of news coverage placed in this category. To do so we apply a structural topic model to discover the types of coverage that fall under the foreign affairs label. We view this examination as a supplement to the supervised learning portion of the study by indicating the types of foreign affairs coverage that fell into this broader category.

This approach requires specifying the number of topics to be estimated prior to fitting the models. After fitting models with various numbers of topics and reading the resulting topics and their fit with various news categories, we settled on a 42-topic model to capture the variety of coverage types available from the media in this area while still avoiding the creation of too many categories. The table below shows the visits-weighted share of the articles in the foreign affairs category that fell into these topics, a label assigned based on reading articles with a high proportion of their content in that topic and the top frex words associated with that topic. We list the topics with a clear substantive relevance from 1-29 and display other topics with less clear associations to foreign affairs after those. 
Table D6: Topics Present in Foreign Affairs Coverage

\begin{tabular}{|c|c|c|c|}
\hline & Label & Share & Top Frex Words \\
\hline 1 & U.S. Executive Branch in Foreign Policy & 0.043 & secretari,administr,chief,tillerson,depart \\
\hline 2 & International Trade & 0.040 & food,economi,cut,industri,product \\
\hline 3 & China (esp. Trade) & 0.039 & china,trade,chines,beij,world \\
\hline 4 & UK (esp. Brexit) & 0.036 & parliament,brexit,british,parti,labour \\
\hline 5 & Islam & 0.035 & muslim,christian,religi,violenc,cultur \\
\hline 6 & Cybersecurity & 0.034 & inform,materi,document,system,comput \\
\hline 7 & North Korean Missile Test & 0.034 & nuclear,missil,korea,test,ballist \\
\hline 8 & Mueller Investigation & 0.033 & manafort,investig,mueller,lawyer,attorney \\
\hline 9 & Trump Interactions w/ Foreign Leaders & 0.032 & trump,donald,trump,ivanka,president-elect \\
\hline 10 & Trump Campaign Russia Contact & 0.028 & flynn,kushner,session,kislyak,advis \\
\hline 11 & International Finance & 0.026 & data,money,financi,compani,corpor \\
\hline 12 & Terrorist Attacks & 0.024 & polic,attack,bridg,kill,incid \\
\hline 13 & ISIS/Iraq & 0.024 & isi,iraqi,iraq,islam,milit \\
\hline 14 & Trump Admin Travel Ban & 0.023 & refuge,ban,court,order,travel \\
\hline 15 & World Education/Health & 0.023 & school,univers,educ,student,women \\
\hline 16 & Russia & 0.021 & putin,vladimir,russia,moscow,russian \\
\hline 17 & CIA on Foreign Interference & 0.021 & elector,hack,cia,intellig,wikileak \\
\hline 18 & Obama Interactions w/ Foreign Leaders & 0.020 & obama,barack,washington, white,ladi \\
\hline 19 & US Military Deployments & 0.020 & armi,plane,command,ship,navi \\
\hline 20 & Travel Ban Protests & 0.016 & protest,demonstr,ralli,mayor,gather \\
\hline 21 & U.S. Border & 0.016 & border,mexico,immigr,drug,migrant \\
\hline 22 & European Union & 0.014 & germani,franc,macron,german,merkel \\
\hline 23 & Syrian Civil War & 0.013 & syrian,chemic,assad,syria,rebel \\
\hline 24 & Israel/Palestine & 0.011 & palestinian,jerusalem,isra,israel,netanyahu \\
\hline 25 & Trump Middle East Visit & 0.011 & saudi,arabia,iran,iranian,middl \\
\hline 26 & North Korean Domestic Politics & 0.009 & pyongyang,kim,jong,korean,north \\
\hline 27 & Climate Policy & 0.006 & freedom,climat,chang,environment,warm \\
\hline 28 & World Comparisons (Health/Economy) & 0.006 & tax,averag,cost,rate,insur \\
\hline 29 & World Comparisons (Military) & 0.002 & tank,personnel,strength,naval,popul \\
\hline 30 & Speech/Transcript/Oped Language & 0.094 & think,re,dont,thing,realli \\
\hline 31 & Obituary Language & 0.049 & friend,didnt,father,son,love \\
\hline 32 & Media Outlet References & 0.041 & media,news,fox,twitter,comment \\
\hline 33 & Polling/Election Discussion & 0.028 & vote,poll,regist,ballot,percent \\
\hline 34 & U.S. Congress & 0.027 & law,bill,congress,constitut,legisl \\
\hline 35 & 2016 Presidential Election & 0.027 & republican,clinton,gop,candid,sen \\
\hline 36 & Media Advertising & 0.025 & articl,daili,version,wrote,headlin \\
\hline 37 & British Royalty & 0.014 & princ,game,william,royal,england \\
\hline 38 & Advertising & 0.012 & updat,essenti,pleas,check,full \\
\hline 39 & Weather & 0.010 & florida,flood,island,texa,storm \\
\hline 40 & Image Captions & 0.006 & imag,violent,getti,joe,per \\
\hline 41 & Foreign Entertainment & 0.003 & hill,globe,hotel,california,award \\
\hline 42 & Poll/Election Results & 0.002 & approv,adult,like,favor,oppos \\
\hline
\end{tabular}


This reveals a number of topics with clear implications for foreign affairs. This includes discussions of various aspects of U.S. foreign policy (e.g., executive branch and bureaucratic staffing, trade with China, the Trump administration's Travel Ban and the protests that followed). It also includes multiple topics that address aspects of foreign interference in the 2016 Presidential elections (e.g., the CIA's initial report on election interference, postelection commentary by Vladimir Putin on the issue and the Mueller investigation).

These topics are not confined to international events that directly involved the United States. This coverage also contains discussion of events outside the United States such as discussion surrounding Brexit and the European Union. Finally, there are various forms of thematic coverage on issues like international trade, media discussions of Islam and religion around the world, and terrorist attacks.

Below this group of topics there are other topics that emerged from the model, but have less clear implications for foreign affairs, this includes ancillary language related to advertisements or image captions that remained in the text files, a small share of topics that appear to have incorrectly placed in this category (e.g., discussion of British Royalty and weather reporting) as well as substantive topics, such as discussion of the 2016 Presidential election or activity in the U.S. Congress that co-occurred with discussion of foreign affairs. 


\section{E Appendix E: Form of Foreign Media Exposure (Ad- ditional Evidence)}

This section considers several alternative comparisons of differences in media exposure between foreign and domestic media.

\section{E.1 "Other" Coverage as an Outcome}

First, we consider the label of "Other" political coverage as an outcome variable. This shows the foreign media exposure is more oriented towards this category than is domestic media use. In other words, media users do not simply substitute domestic and foreign political coverage when moving between these sources but also encounter more non-political content.

Table E1: "Other" Political Coverage as Outcome

\begin{tabular}{lc}
\hline Foreign Website Visit & Other Political Coverage \\
& \multicolumn{1}{c}{$\begin{array}{c}0.116^{*} \\
(0.019)\end{array}$} \\
\hline Observations & $3,386,306$ \\
\hline Note: & ${ }^{*} \mathrm{p}<0.05$ \\
& Robust Standard Errors, Clustered by Individual \\
& Models Include Person and Day Fixed Effects
\end{tabular}

This greater focus on non-political coverage when visiting foreign sources aligns with findings to emerge in other content analyses of online news exposure (e.g., Budak et al. 2016, Table 1 shows that a much lower percentage of visits to the BBC website went to political coverage relative to the domestic news websites they considered).

\section{E.2 Bivariate Comparison}

The table below displays differences in exposure after removing the additional covariates discussed in the main text. This is results in a bivariate comparison of whether the typical foreign media visit differed from the typical domestic media visit. Here the coefficient on foreign media use and exposure to foreign affairs coverage is smaller, though still positive, 
and does not reach conventional levels of statistical significance. There continues to be relatively more exposure to "Other" non-political topics and less to U.S. domestic politics during foreign media visits.

Table E2: News Source and Coverage Type (Bivariate)

\begin{tabular}{lccc}
\hline & Foreign Affairs Coverage & U.S. Domestic Political Coverage & Other Coverage \\
\hline Foreign Website Visit & 0.041 & $-0.258^{*}$ & $0.217^{*}$ \\
& $(0.023)$ & $(0.012)$ & $(0.030)$ \\
\hline Observations & $3,386,306$ & $3,386,306$ & $3,386,306$ \\
\hline Note: & ${ }^{*} \mathrm{p}<0.05$ & \\
& Robust Standard Errors, Clustered by Individual &
\end{tabular}

While it is important to note the weaker pattern of findings in the bivariate regression, they remain consistent with the within-subject specification presented in the main text, even as they make a less clear comparison of how the same types individuals behave in either setting by not accounting for differences in the types of people who visit these sites.

\section{E.3 Using Person-Day Fixed Effects}

The next table includes a more restrictive analysis with a separate intercept for each individual in the sample on each day. These person-day fixed effects accounts for any situations in which particular events on a given day influence an individual's likelihood of consuming certain types of news coverage.

Table E3: News Source and Coverage Type (Person-Day Fixed Effects)

\begin{tabular}{lccc}
\hline & Foreign Affairs Coverage & U.S. Domestic Political Coverage & Other Coverage \\
\hline Foreign Website Visit & $0.064^{*}$ & $-0.188^{*}$ & $0.124^{*}$ \\
& $(0.014)$ & $(0.013)$ & $(0.019)$ \\
\hline Observations & $3,386,306$ & $3,386,306$ & $3,386,306$ \\
\hline Note: & ${ }^{*} \mathrm{p}<0.05$ & \\
& $\begin{array}{l}\text { Robust Standard Errors, Clustered by Individual } \\
\text { Models Include Person-Day Fixed Effects }\end{array}$ &
\end{tabular}

As in the other specifications we continue to observe a pattern in which foreign media exposure is more internationally oriented than visits to domestic news sources. 


\section{E.4 Dropping Daily Mail}

The Daily Mail is somewhat of an outlier in our data. It is a foreign news site with a large presence, but also predominately focuses on entertainment coverage in contrast to the types of news sources that motivated past comparisons between domestic and foreign media environments. Here we show our results on the distinctive nature of foreign news exposure are strengthened when we exclude the Daily Mail a point consistent with our environmental count of political news exposure from these sources.

Table E4: News Source and Coverage Type (Dropping Daily Mail)

\begin{tabular}{lccc}
\hline & Foreign Affairs Coverage & U.S. Domestic Political Coverage & Other Coverage \\
\hline Foreign Website Visit & $0.110^{*}$ & $-0.198^{*}$ & $0.087^{*}$ \\
& $(0.016)$ & $(0.014)$ & $(0.020)$ \\
\hline Observations & $3,249,102$ & $3,249,102$ & $3,249,102$ \\
\hline Note: & ${ }^{*} \mathrm{p}<0.05$ & \\
& Robust Standard Errors, Clustered by Individual & \\
& Models Include Person and Day Fixed Effects &
\end{tabular}

\section{E.5 Comparison to Domestic Outlets with High Capacity for For- eign Affairs Coverage}

Our final comparison focuses on a "tough test" of the comparison between foreign and domestic media sources. Specifically, we compare foreign media sources to the Washington Post, New York Times, Wall Street Journal and Los Angeles Times. We select these out-

lets because they had the greatest number of foreign correspondents and reporters for U.S. newspapers in the 2018 edition of the News Media Yellowbook, a media staffing directory.

These outlets are not reliant on wire copy to cover foreign affairs and, relative to other domestic media sources, have an institutional structure designed to promote foreign affairs coverage. For this reason they represent a favorable setting for the public to encounter foreign affairs coverage from the domestic media. 
Table E5: News Source and Coverage Type (Trimmed Domestic Sample)

\begin{tabular}{lccc}
\hline & Foreign Affairs Coverage & U.S. Domestic Political Coverage & Other Coverage \\
\hline Foreign Website Visit & $0.073^{*}$ & $-0.209^{*}$ & $(0.009)$ \\
& $(0.013)$ & 831,538 & $0.137^{*}$ \\
Observations & 831,538 & & 831,538 \\
\hline Note: & ${ }^{*} \mathrm{p}<0.05$ & \\
& Robust Standard Errors, Clustered by Individual \\
& Models Include Person and Day Fixed Effects &
\end{tabular}

Even in this more limited comparison the shift from domestic to foreign sources generates a relative increase in exposure to foreign affairs coverage and a decrease in attention to U.S. domestic politics. 


\section{F Appendix F: Supply of News from Foreign and Do- mestic Media}

To assess the supply of information from these news sources, we drew a sample of 1,200 homepage articles (600 from domestic media, 600 from foreign media) from this time period.

The news sources under consideration were selected based on their high-levels of web traffic within their respective categories. For domestic sources we consider: cnn.com, nytimes.com, washingtonpost.com, huffingtonpost.com, usatoday.com, and foxnews.com. For the foreign sources we consider: dailymail.co.uk, theguardian.com, bbc.com, telegraph.co.uk, independent.co.uk, and rt.com

We examine the coverage on the homepage of these sites on ten randomly selected days during this time period: $11 / 9 / 2016,12 / 13 / 2016,3 / 12 / 2017,3 / 26 / 2017,5 / 20 / 2017,7 / 20 / 2017$, 8/2/2017, 9/13/2017, 11/20/2017, 12/20/2017. We used the Internet Archive's Wayback Machine to examine the homepage at the closest capture available to 12:00PM that day. We then recorded the headlines of the ten most prominent news stories on the homepage at that time. This involved working down from the top of the page and across from left to right until the ten story quota was reached. We believe this approach captures the supply of information available and emphasized on a news website on a a given day.

We then used crowd-sourcing to evaluate the content of these headlines. We employed the same procedure that was used in the supervised learning portion of the study. Each headline received five topic labels from different coders. As the high level's of Krippendorf's alpha indicate, there is a high degree of reliability to this coding scheme, whether considering the pooled set of articles or separately assessing article's from foreign and domestic sources. 
Table F1: Intercoder Reliability for Headlines (3 Category Scheme)

\begin{tabular}{rrrr}
\hline & Pooled & Foreign Sources & Domestic Sources \\
\hline Krippendorf's $\alpha$ & 0.72 & 0.70 & 0.72 \\
No. Articles & 1200.00 & 600.00 & 600.00 \\
\hline
\end{tabular}

We produce a final label for each headline based on a majority vote among the labels. As discussed in the main text, this shows the the supply of news from foreign media sources is substantially more internationally-oriented and less focused on U.S. domestic politics than the coverage available from domestic news sources. Table F2 shows the differences in the supply of information available from these sources by regressing the label a story received on an indicator variable for whether it appeared in a foreign media outlet. This shows that foreign outlets offer a substantially higher supply of foreign affairs coverage and substantially less coverage of U.S. domestic politics, a similar pattern to what we observe when examining news consumption from these websites.

Table F2: Difference in Coverage Supply Between Domestic and Foreign Sources

\begin{tabular}{lrrr}
\hline & Foreign Affairs Coverage & U.S. Domestic Political Coverage & Other Coverage \\
\hline (Intercept) & $0.14^{*}$ & $0.51^{*}$ & $0.35^{*}$ \\
& $(0.02)$ & $(0.02)$ & $(0.02)$ \\
Foreign Media Outlet & $0.19^{*}$ & $-0.29^{*}$ & $0.10^{*}$ \\
& $(0.02)$ & $(0.03)$ & $(0.03)$ \\
\hline$N$ & 1200 & 1200 & 1200 \\
\hline Standard errors in parentheses & & & \\
${ }^{*}$ indicates significance at $p<0.05$ & & &
\end{tabular}

